OPEN ACCESS

*Red Sea Research Center, King Abdullah University of Science and Technology (KAUST), Thuwal 239556900 , Kingdom of Saudi Arabia

Corresponding author email address: susana.agusti@kaust.edu.sa 10.5339/qproc.2015.qulss2015.5

Copyright: 2015 Susana Agusti , Moira Llabrés, Luis M. Lubián, Enrique Moreno Ostos, Marta Estrada, Carlos M. Duarte, Maria I. Cerezo, licensee Bloomsbury Qatar Foundation Journals. This is an open access article distributed under the terms of the Creative Commons Attribution license CC BY 4.0, which permits unrestricted use, distribution and reproduction in any medium, provided the original work is properly cited.

\author{
Qatar University Life Science Symposium-QULSS 2015 \\ Global Changes: The Arabian Gulf Ecosystem
}

\section{Multiple stressors for oceanic primary production}

\author{
Susana Agusti * , Moira Llabrés, Luis M. Lubián, Enrique Moreno-Ostos, \\ Marta Estrada, Carlos M. Duarte, Maria I. Cerezo
}

Marine ecosystems are increasingly exposed to stress factors of anthropogenic origin that change their function, structure and services they deliver society. Climate change occurs simultaneously with other changes in the environment acting jointly in a context of global environmental change. For oceanic phytoplankton communities, the research conducted so far has identified stress factors associated with global change and their impact individually (warming, acidification, increased UVB radiation, pollutants). But when several stressors act simultaneously interactions and responses are not equal to the sum of individual impacts, but may have synergistic effects (the effects are multiplied) or antagonistic (cancel out the effects) that hinder predictions of the vulnerability of ecosystems to global change. Here we will examine the vulnerability of oceanic primary producers to the accumulation of different stressors associated with global change. The trend for autotrophic picoplankton to increase with temperature in the ocean has led to predictions that autotrophic picoplankton abundance will increase with warming. However, it is documented a trend towards a decline in productivity, due to declined autotroph biomass and production with warming and the associated stratification in the subtropical ocean. Models predicting an increase in abundance are in contradiction with the reported decrease in productivity in several oceanic areas, and associate oligotrophication. Here we perform a global study to analyze the relationships of autotrophic picoplankton with oceanic temperature, nutrients, underwater light and ultraviolet B (UVB) radiation, and productivity. We built a model to project the future changes of autotrophic picoplankton considering multiple environmental changes in future climate scenarios for the subtropical gyres. We considered increased water temperature, and associated changes in productivity and underwater light and UVB. The model show that warming and the decrease in water productivity, with the associated increase in photosynthetic active radiation and UV-B radiation at depth, are expected to result in a decline by 18 to $42 \%$ in the abundance of autotrophic picoplankton. We also predict an increase in the importance of deep blooms at moderate warming, that models based solely in temperature changes failed to predict. We will examine also the vulnerability of oceanic primary producers to the accumulation of different stressors associated with global change as warming, increased UVB radiation and persistent organic pollutants, and explore whether there are synergistic and antagonistic responses of due to join stresses impacting them.

Cite this article as Susana Agusti , Moira Llabrés, Luis M. Lubián, Enrique Moreno-Ostos, Marta Estrada, Carlos M. Duarte, Maria I. Cerezo, Multiple stressors for oceanic primary production, Qatar University Life Science Symposium 2015, http://dx.doi.org/10.5339/qproc.2015.qulss2015.5 